\title{
Methicillin-Resistant Staphylococcus aureus Infection: An Independent Risk Factor for Mortality in Patients with Poststernotomy Mediastinitis
}

\author{
Serap Şimşek Yavuz ${ }^{a}$ Ayfer Şensoy ${ }^{b}$ Sabahat Çeken ${ }^{b}$ Denef Deniz ${ }^{b}$ \\ İbrahim Yekeler ${ }^{c}$ \\ a Department of Infectious Diseases and Clinical Microbiology, Istanbul Faculty of Medicine, Istanbul University, and \\ Departments of ${ }^{b}$ Infectious Disease and Clinical Microbiology and ${ }^{\mathrm{C}}$ Cardiovascular Surgery, Siyami Ersek Thoracic \\ and Cardiovascular Surgery Hospital, Istanbul, Turkey
}

\section{Key Words}

Poststernotomy mediastinitis · Mortality .

Methicillin-resistant Staphylococcus aureus

\section{Abstract}

Objective: The mortality rate of patients with poststernotomy mediastinitis remains very high. The aim of this study was to identify the risk factors associated with mortality in these patients. Subjects and Methods: Surveillance of sternal surgicalsite infections including mediastinitis was carried out for adult patients undergoing a sternotomy between 2004 and 2012 . Criteria from the US Centers for Disease Control and Prevention were used to make the diagnosis. All data on patients with a diagnosis of mediastinitis who were included in the study and on mortality risk factors were obtained from the hospital database and then analyzed using SPPS 16.0 for Windows. Results: Of the 19,767 patients undergoing open heart surgery, 117 (0.39\%) had poststernotomy mediastinitis; 32\% of these $117 \mathrm{died}$. The independent risk factors for mortality were methicillin-resistant Staphylococcus aureus (MRSA) [odds ratio (OR) 12.11 and 95\% confidence interval (CI) 3.1546.47], intensive-care unit stays $>48 \mathrm{~h}$ after the first operation

\begin{tabular}{ll}
\hline KARGER & $\begin{array}{l}\text { (c) 2014 S. Karger AG, Basel } \\
1011-7571 / 14 / 0236-0517 \$ 39.50 / 0\end{array}$ \\
$\begin{array}{l}\text { E-Mail karger@karger.com } \\
\text { www.karger.com/mpp }\end{array}$ & $\begin{array}{l}\text { This is an Open Access article licensed under the terms of the } \\
\text { Creative Commons Attribution-NonCommercial 3.0 Un- } \\
\text { ported license (CC BY-NC) (www.karger.com/OA-license), } \\
\text { applicable to the online version of the article only. Distribu- } \\
\text { tion permitted for non-commercial purposes only. }\end{array}$
\end{tabular}

(OR 11.21 and $95 \% \mathrm{Cl} 3.24-38.84$ ) and surgery that included valve replacement (OR 6.2 and $95 \% \mathrm{Cl} 1.44-27.13$ ). The mortality rate decreased significantly, dropping from $38 \%$ (34/89) between 2004 and 2008 to 14\% (4/28) between 2009 and 2012 ( $p=0.018)$. Conclusion: In this study, elimination of MRSA from the hospital setting decreased the rate of mortality in patients with poststernotomy mediastinitis.

(C) 2014 S. Karger AG, Basel

\section{Introduction}

Although the incidence of poststernotomy mediastinitis is low and is reported to range from 0.5 to $5 \%$, it is a potentially devastating complication of cardiac surgery, and is associated with increased mortality, morbidity and cost [1-3]. In addition, the great number of cardiac operations performed all over the world and the high rate of mortality associated with mediastinitis (20-33\%) make this infection an important topic for study [4-7].

Mediastinitis secondary to cardiothoracic surgery is primarily caused by Gram-positive cocci, and staphylococci are responsible for infection in $>60 \%$ of cases $[1,8]$. 
Risk factors for poststernotomy mediastinitis have been analyzed in numerous studies, and these include diabetes mellitus, obesity, emergency surgery, heart transplant surgery, complex surgery, the use of internal mammary arteries in coronary artery bypass grafting (CABG), a prolonged operative time, blood transfusion and the indiscriminate use of electrocautery $[1,9]$.

Several studies have identified the risk factors leading to death in patients with poststernotomy mediastinitis [4-7]. In this study, we analyzed the risk factors for mortality over a 9-year period in a group of 117 patients who developed mediastinitis after open heart surgery.

\section{Subjects and Methods}

All adult patients who underwent a sternotomy at the Siyami Ersek Thoracic and Cardiovascular Surgery Hospital from 1 January 2004 to 30 June 2012 and who developed mediastinitis were included in the study. Surveillance of sternal surgical-site infections was conducted throughout the study period using a patient- and laboratorybased surveillance method. The US Centers for Disease Control and Prevention (CDC) criteria for mediastinitis were used in the diagnosis [10]. Due to the presence of a foreign body (sternal wire) in the sternum after the sternotomy, patients with mediastinitis that occurred in the first postoperative year were included in the study.

Data used for the risk factor analysis were retrospectively obtained from the hospital database. The following variables were recorded: age, gender, American Society of Anesthesiologists (ASA) score, comorbid conditions before sternotomy (diabetes mellitus, chronic renal failure or congestive heart failure), type of operation, operative and postoperative characteristics [type of bypass grafts used, intra-aortic balloon pump (IABP) and vasopressor usage], the duration of the stay in the intensive-care unit (ICU), a second surgical intervention for bleeding or tamponade before infection, the causative microorganisms, the results of wound and blood culture, the time between surgery and the diagnosis of mediastinitis, antibiotic regimens, the duration of the second surgical intervention for infection and the time between infection and death, laboratory values (levels of blood sugar, blood urea nitrogen, creatinine, C-reactive protein, serum aspartate aminotransferase and hemoglobin, and platelet and white blood cell counts) at the time of diagnosis of the infection, the type of second surgical intervention for infection [standard therapy with primary closure, standard therapy with Robicsek closure (bilateral and longitudinal parasternal wiring) or omental/ muscle flap], the use of a wound vacuum (VAC) for treatment and the total length of hospital stay. During the study period, the standard surgical therapy for poststernotomy mediastinitis at our hospital was sternal debridement and drainage, with either a primary or Robicsek closure technique. In the case of suspected mediastinitis, blood and sternal drainage cultures were obtained from patients and empirical antibiotics were subsequently prescribed, usually consisting of vancomycin and an agent that was active against Gram-negative rods (e.g. cefoperazone + sulbactam, ciprofloxacin or imipenem). Antibiotics were deescalated according to the culture and sensitivity results. The minimum inhibitory concentration of methicillin-resistant Staphylococcus aureus (MRSA) strains had not yet been determined
Table 1. Bacteremia and inhospital mortality in mediastinitis patients, according to the causative microorganism

\begin{tabular}{lclc}
\hline $\begin{array}{l}\text { Causative } \\
\text { microorganism }\end{array}$ & $\mathrm{n}(\%)$ & $\begin{array}{l}\text { Bacteremia, } \\
\mathrm{n}(\%)\end{array}$ & $\begin{array}{l}\text { Mortality, } \\
\mathrm{n}(\%)\end{array}$ \\
\hline $\begin{array}{l}\text { MRSA } \\
\begin{array}{l}\text { Enterobacteriaceae } \\
\text { Coagulase-negative }\end{array}\end{array}$ & $47(40)$ & $32(68)$ & $23(49)$ \\
$\begin{array}{l}\quad \text { staphylococci } \\
\text { Methicillin-sensitive } \\
\quad \text { S. aureus }\end{array}$ & $19(16)$ & $3(15)$ & $2(11)$ \\
$\begin{array}{l}\text { Others } \\
\text { Total }\end{array}$ & $13(11)$ & $4(30)$ & $2(15)$ \\
& $117(15)$ & $7(41)$ & $5(29)$ \\
\hline
\end{tabular}

between 2004 and 2008, and daptomycin was not available in Turkey until 2010. Since all of the MRSA isolates were found to be resistant to rifampicin and gentamicin during our study period, vancomycin alone was used to treat all except for 3 patients with MRSA mediastinitis. Due to its nephrotoxic side effects, vancomycin was changed to teicoplanin for 2 patients, even though the standard dose of teicoplanin can be less efficacious than vancomycin against MRSA [11]. Linezolid, a bacteriostatic agent, was used for 1 patient.

MRSA-specific infection control interventions that were undertaken during the study period from 2004 to 2012, along with general infection control measures at different time intervals were the surveillance of MRSA sternal surgical-site infections and feedback, preoperative nasal MRSA screening, decolonization with mupirocin and isolation of patients infected with or colonized by MRSA. Information about the infection control interventions that were undertaken to decrease the rate of sternal surgical-site infections in our hospital has been reported previously [12]. Mortality was defined as inhospital death. Mediastinitis was regarded as the sole reason for death if it was the first serious complication during the postoperative period, and it was regarded as contributing to death if it followed other serious complications such as bleeding or central nervous system complications during the postoperative period.

Statistical analyses were done using SPSS for Windows, version 16.0. The $\chi^{2}$ and Student $t$ tests were used for the univariate analysis of categorical and continuous variables of patient characteristics, respectively. Independent risk factors for mortality were determined by multiple logistic regression analysis. Variables found to be significant $(\mathrm{p}<0.05)$ in the univariate analysis or reported to be risk factors for mortality in the literature were included in the logistic regression analysis.

\section{Results}

Open heart surgery was performed on 19,767 patients. This surgery included CABG in 13,628 (69\%) patients, valve replacement in 3,481 (18\%), aortic surgery in 1,098 (18\%), valve replacement and CABG in 773 
Table 2. Characteristics of mediastinitis patients with and without mortality

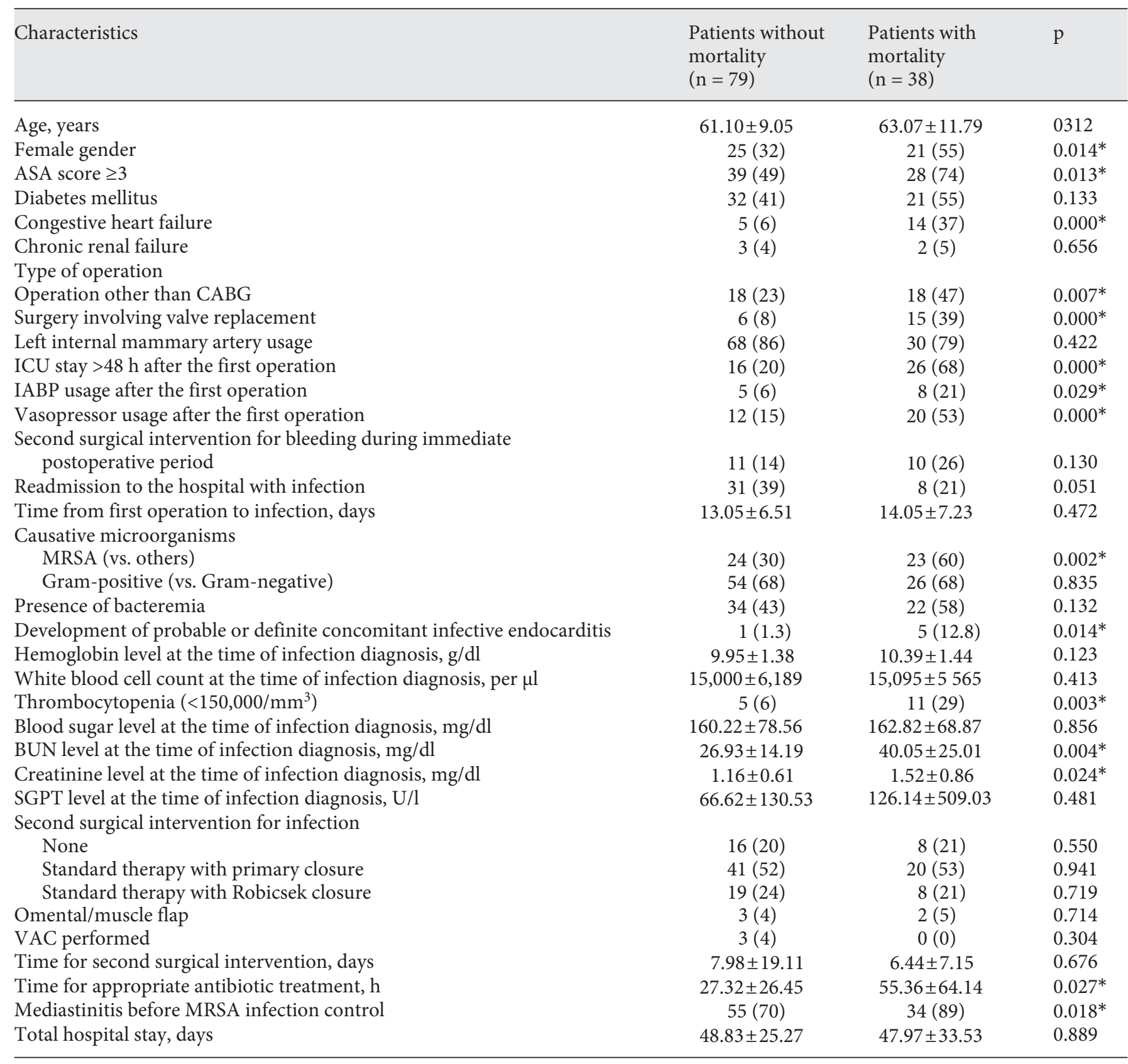

Values are mean \pm SD or $\mathrm{n}(\%)$. BUN $=$ Blood urea nitrogen. ${ }^{*}$ Statistically significant.

(4\%) and other operations in 787 (4\%). The mean time from the first operation to infection occurrence was $13.37 \pm 6.74$ days (range $3-32$ ). One hundred and seventeen patients $(0.59 \%)$ were diagnosed with mediastinitis; bacteremia developed in $56(48 \%)$ of these. The causative microorganisms and their respective bactere- mia and mortality rates are shown in table 1 . Of the 117 patients, 38 (32\%) died during their hospital stay or upon readmission to the hospital. The mortality rate was highest for mediastinitis caused by MRSA (23/49 cases or $49 \%$ ) and lowest for that caused by coagulase-negative staphylococci $(2 / 15$ cases or $11 \%)$. The duration 
Table 3. Results of logistic regression analysis of risk factors of mortality in mediastinitis cases

\begin{tabular}{|c|c|c|c|c|}
\hline \multirow[t]{2}{*}{ Variables } & \multirow[t]{2}{*}{$\mathrm{p}$ value } & \multirow[t]{2}{*}{ OR } & \multicolumn{2}{|c|}{$95 \% \mathrm{CI}$} \\
\hline & & & lower & upper \\
\hline Mediastinitis due to MRSA & 0.000 & 12.117 & 3.159 & 46.475 \\
\hline Female gender & 0.067 & 3.064 & 0.925 & 10.150 \\
\hline ICU stay longer than $48 \mathrm{~h}$ after the first operation & 0.000 & 11.219 & 3.240 & 38.849 \\
\hline Creatinine level $>1.1 \mathrm{mg} / \mathrm{dl}$ at the time of infection diagnosis & 0.068 & 3.081 & 0.919 & 10.325 \\
\hline Platelet number $>150,000 / \mu \mathrm{l}$ at the time of infection diagnosis & 0.062 & 4.716 & 0.926 & 24.012 \\
\hline Surgery involving valve replacement & 0.014 & 6.252 & 1.441 & 27.138 \\
\hline
\end{tabular}

(mean \pm SD) from the beginning of infection to death was $45.42 \pm 102.29$ days (median 17.5 and range 1-630). Mediastinitis was the sole cause of death in 15 patients (40\%) and contributed to death in 23 (60\%). Infective endocarditis was diagnosed in 6 of the 117 patients as a complication of bacteremic mediastinitis. One of these 6 patients had definite and 5 had probable concomitant infective endocarditis, according to the Duke criteria. Patients with a diagnosis of endocarditis secondary to bacteremic mediastinitis did not undergo redo valve replacement surgery because of the unacceptably high rate of operative mortality. The ASA scores of patients did not differ during the study period $(\mathrm{p}=0.091)$.

Based on the univariate analysis, risk factors for mortality with mediastinitis were female gender, an ASA score $\geq 3$, congestive heart failure before surgery, any operation other than $\mathrm{CABG}$, any operation involving valve replacement, an ICU stay $>48 \mathrm{~h}$ after the first operation, vasopressor and IABP usage after the first operation, blood urea nitrogen and creatinine levels and platelet count at the diagnosis of infection, mediastinitis caused by MRSA, the development of probable or definite concomitant infective endocarditis and the duration of appropriate antibiotic treatment $(\mathrm{p}<0.05$; table 2$)$.

Based on the multivariate analysis, the independent risk factors for mortality with mediastinis were MRSA as the causative agent [odds ratio (OR) 12.11 and $95 \%$ confidence interval (CI) 3.15-46.47], an ICU stay $>48 \mathrm{~h}$ after the first operation (OR 11.21 and 95\% CI 3.24-38.84) and surgery including valve replacement (OR 6.2 and $95 \%$ CI 1.44-27.13; $\mathrm{p}<0.05$; table 3).

A comparison of the characteristics of patients with and without MRSA infection did not reveal any difference between the groups ( $p>0.05)$ except for rates of bacteremia $(\mathrm{p}<0.001)$ and mortality $(\mathrm{p}=0.002)$ which were higher in the MRSA group.
MRSA infections at the sternal surgical site decreased significantly in 2009 owing to the effectiveness of the continuous infection control program at our hospital. The mortality rate also decreased significantly, from $35 \%$ $(34 / 89)$ between 2004 and 2008 to $14 \%(4 / 28)$ between 2009 and $2012(\mathrm{p}=0.018)$. The rate of MRSA mediastinitis among patients after open heart surgery, the rate of preoperative nasal MRSA, the proportion of all hospital nosocomial infections caused by MRSA and the mortality and MRSA rates among mediastinitis cases are shown in figure 1.

None of the variables analyzed for mortality risk were significantly different between the patients who underwent surgery before MRSA mediastinitis was eliminated in 2009 and those who underwent surgery after this $(p>0.05)$, except for MRSA $(p=0.000)$, female gender $(p=0.029)$ and mortality rates $(\mathrm{p}=0.018)$.

\section{Discussion}

The $32 \%$ overall mortality rate after median sternotomy mediastinitis in our study is similar to the rate reported in other recent studies [4-6]. We also showed that MRSA infection was an independent risk factor for inhospital mortality due to poststernotomy mediastinitis. Previous reports have also described MRSA infection as an independent risk factor for death, increased mortality and treatment failure linked to poststernotomy mediastinitis, even when compared to methicillinsusceptible $S$. aureus infection [6,13-17]. Morisaki et al. [15] showed that MRSA infection was the factor most strongly associated with increased inhospital mortality, and Karra et al. [6] reported it to be the factor most strongly associated with 1-year mortality after poststernotomy mediastinitis. MRSA infections have been en- 


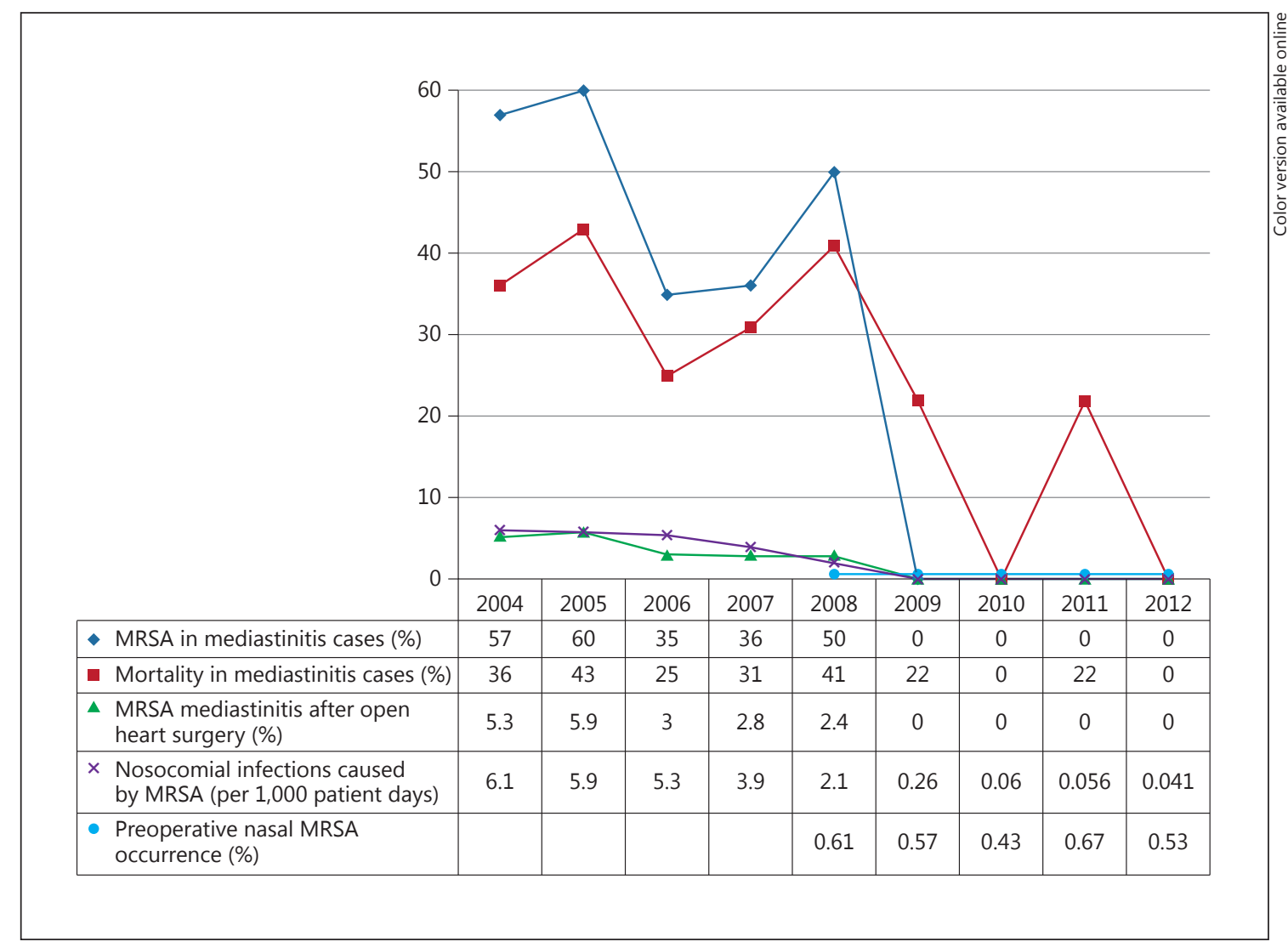

Fig. 1. The rates of mortality and MRSA in cases of mediastinitis, the rate of MRSA mediastinitis after open heart surgery and the incidence of all nosocomial infections caused by MRSA during the study period.

demic in our hospital since 1995. Based on an epidemiological analysis [18], infection control interventions were initiated in 1998. However, it took some time for all of the interventions to be implemented, so MRSA infections were not completely controlled until 2009 [12]. Although nosocomial infections (mainly pneumoniae) caused by MRSA occur infrequently, we did not see any mediastinitis caused by MRSA after 2008 (fig. 1). The mortality rate of mediastinitis also dropped significantly after 2008. This decline further supports the notion that MRSA is an independent risk factor for mortality in patients with mediastinitis.

The reasons for the increased mortality rate among patients with MRSA infections are not clearly understood. There is no evidence to suggest that MRSA strains are more virulent than methicillin-susceptible $S$. aureus strains, although there is evidence to suggest that vancomycin may be an inferior antistaphylococcal antibiotic compared to semisynthetic penicillins, especially for the treatment of deep-seated S. aureus infections [19]. Based on the finding of higher mortality rates from mediastinitis due to MRSA in our study and as mentioned in earlier studies and the current lack of highly active anti-MRSA antimicrobials, this microorganism is considered to be dangerous, in particular for patients undergoing cardiac surgery. Hence, every effort should be made to eradicate MRSA infections from cardiac-surgery units.

The finding that valve replacement surgery is an independent risk factor for mortality in patients with mediastinitis in our study is similar to other studies $[5,20]$. A probable reason for the high mortality rate in mediastinitis with valve replacement surgery might be the severity of the underlying illness. In our study, the ASA scores were higher in patients with valve replacement surgery than in patients with other types of open heart surgery. In addition, even in the absence of any complication, the expected mortality rates of $5 \%$ with valve replacement surgery and $10 \%$ with combined $\mathrm{CABG}$ and valve replacement surgery are higher than the $2 \%$ when CABG surgery only is performed [21]. Forty percent of our patients with valve replacement sur- 
gery underwent simultaneous CABG. The addition of mediastinitis to the picture could have caused an even higher mortality rate after this combined surgery, which is already associated with a high mortality rate.

Another reason for the high mortality rate in patients with valve replacement surgery and mediastinitis could be the development of endocarditis secondary to the mediastinitis. While the univariate analysis showed that the development of infective endocarditis is a risk factor for mortality, the multivariate analysis did not confirm this. Infective endocarditis was diagnosed in 6 of our patients. In patients with mediastinitis, prosthetic valves can be infected either by direct inoculation from the infected mediastinum or during concurrent bacteremia. The high rate of $50 \%$ bacteremia in patients with mediastinitis in our study confirmed that reported by Mekontso-Dessap et al. [13]. Unfortunately, once established, prosthetic-valve endocarditis leads to death in almost half of patients; this occurs particularly in cases of nosocomial infection $[22,23]$. These data underline the importance of preventing mediastinitis (and bacteremia) in patients with prosthetic valves.

Our finding that a longer stay in ICU after the first operation is associated with increased mortality is similar to that of another study [6]. This could probably be a marker for patients with increased immediate perioperative complications, such as bleeding, organ failure, hypotension, neurologic sequelae or second surgical intervention, which predispose such patients to mediastinitis and death. Patients who experience these complications and have to stay in the ICU for longer periods deserve special attention in order to prevent infectious complications and high mortality rates as a consequence.

VAC therapy [24] has been reported to be efficient in the treatment of poststernotomy mediastinitis. We used the procedure on 3 patients, and all of them survived; however, this is a small number, so we were not able to compare standard therapy with VAC usage in the treatment of mediastinitis.

Our study has some limitations. Although the diagnoses of mediastinitis were made prospectively, variables were retrieved retrospectively from hospital records, and so some variables that might have been associated with death after mediastinitis could not be included in the study. The minimal inhibitory concentrations of MRSA strains and the levels of vancomycin in the blood of patients with MRSA mediastinitis treated with this drug could not be determined during the study period. This meant it was not possible for us to determine whether or not the high mortality rate in these patients was actually due to inefficient treatment of the MRSA infection with vancomycin.

\section{Conclusion}

In this study, MRSA was an independent risk factor of mortality in poststernotomy mediastinitis. Elimination of MRSA from our hospital decreased the rate of mortality in poststernotomy mediastinitis. Mediastinitis was also associated with an increased risk for patients undergoing valve replacement surgery.

\section{References}

1 Van Schooneveld TC, Rupp ME: Mediastinitis; in Mandell GL, Bennett JE, Dolin R, (eds): Principles and Practice of Infectious Diseases, ed 7. Philadelphia, Churchill Livingstone Elsevier, 2010, pp 1173-1183.

2 Bouza E, Hortal J, Muñoz P, et al: Infections following major heart surgery in European intensive care units: there is room for improvement (ESGNI 007 Study). J Hosp Infect 2006; 63:399-405.

-3 Edwards JR, Peterson KD, Mu Y, et al: National Healthcare Safety Network (NHSN) report: data summary for 2006 through 2008, issued December 2009. Am J Infect Control 2009;37:783-805.

4 Lepelletier D, Poupelin L, Corvec S, et al: Risk factors for mortality in patients with mediastinitis after cardiac surgery. Arch Cardiovasc Dis 2009;102:119-225.
5 Trouillet JL, Vuagnat A, Combes A, et al: Acute poststernotomy mediastinitis managed with debridement and closed-drainage aspiration: factors associated with death in the intensive care unit. J Thorac Cardiovasc Surg 2005; 129:518-524.

6 Karra R, McDermott L, Connelly S, et al: Risk factors for 1-year mortality after postoperative mediastinitis. J Thorac Cardiovasc Surg 2006;132:537-543.

7 National Nosocomial Infections Surveillance System: National nosocomial infections surveillance (NNIS) system report, data summary from January 1992 through June 2004, issued October 2004. Am J Infect Control 2004; 32:470-485.

8 Beckmann A, Doebler K, Schaefer E, et al: Sternal surgical site infection prevention - is there any room for improvement? Eur J Cardiothorac Surg 2011;40:347-351.
-9 Simsek Yavuz S, Bicer Y, Yapici N, et al: Analysis of risk factors for sternal surgical site infection: emphasizing the appropriate ventilation of the operating theaters. Infect Control Hosp Epidemiol 2006;27:958-963.

10 Horan TC, Gaynes RP: Surveillance of nosocomial infections; in Mayhall CG (ed): Hospital Epidemiology and Infection Control, ed 3. Philadelphia, Lippincott Williams \& Wilkins, 2004, pp 1659-1702.

-11 Murray JR. Staphylococcus aureus infective endocarditis: diagnosis and management guidelines. Intern Med J 2005;35:S25-S48.

12 Yavuz SŞ, Tarçın O, Ada S, et al: Incidence, aetiology and control of sternal surgical site infections. J Hosp Infect 2013;85:206-212.

13 Mekontso-Dessap A, Kirsch M, Brun-Buisson C, et al: Poststernotomy mediastinitis due to Staphylococcus aureus: comparison of methicillin-resistant and methicillin-susceptible cases. Clin Infect Dis 2001;32:877-883. 
14 Engemann JJ, Carmeli Y, Cosgrove SE, et al: Adverse clinical and economic outcomes attributable to methicillin resistance among patients with Staphylococcus aureus surgical site infection. Clin Infect Dis 2003;36:592-598.

15 Morisaki A, Hosono M, Sasaki Y, et al: Evaluation of risk factors for hospital mortality and current treatment for poststernotomy mediastinitis. Gen Thorac Cardiovasc Surg 2011; 59:261-267.

16 Reddy SL, Grayson AD, Smith G, et al: Methicillin-resistant Staphylococcus aureus infections following cardiac surgery: incidence, impact and identifying adverse outcome traits. Eur J Cardiothorac Surg 2007;32:113-117.
17 Parissis $\mathrm{H}, \mathrm{Al}$-Alao B, Soo A, et al: Risk analysis and outcome of mediastinal wound and deep mediastinal wound infections with specific emphasis to omental transposition. J Cardiothorac Surg 2011,6:111.

18 Simsek Yavuz S, Kocagöz S, Goktas P, et al: Epidemiological analysis of methicillin-resistant Staphylococcus aureus strains isolated from hospital infections by using arbitrarily primed-polymerase chain reaction (APPCR). Flora Dergisi 2001;6:231-239.

19 Cosgrove SE, Sakoulas G, Perencevich EN, et al: Comparison of mortality associated with methicillin-resistant and methicillin-susceptible Staphylococcus aureus bacteremia: a meta-analysis. Clin Infect Dis 2003;36:53-59.

20 Mekontso Dessap A, Vivier E, Girou E, et al: Effect of time to onset on clinical features and prognosis of post-sternotomy mediastinitis. Clin Microbiol Infect 2011;17:292-299.
21 Stahle E, Kvidal P, Nystrom PO, et al: Longterm relative survival after primary heart valve replacement. Eur J Cardiothorac Surg 1997;11:81-91.

22 Rivas P, Alonso J, Moya J, et al: The impact of hospital-acquired infections on the microbial etiology and prognosis of late-onset prosthetic valve endocarditis. Chest 2005;128:764-771.

23 El-Ahdab F, Benjamin DK, Wang A, et al: Risk of endocarditis among patients with prosthetic valves and Stapylococcus aureus bacteremia. Am J Med 2005;118:225-229.

24 De Feo M, Corte AD, Vicchio M, et al: Is post-sternotomy mediastinitis still devastating after the advent of negative-pressure wound therapy? Tex Heart Inst J 2011;38: 375-380. 